
\title{
28 Research Soure \\ Integrated Palliative Care: Triggers for referral to palliative care in ICU patients
}

\section{Yashna Nadkarni ( $\nabla$ yashna.nadkarni@nhs.net)}

Royal Marsden Hospital NHS Trust: Royal Marsden NHS Foundation Trust

\section{Ivana Kukec}

University Hospital Centre Zagreb: Klinicki Bolnicki Centar Zagreb

\section{Pascale Gruber}

Royal Marsden Hospital NHS Trust: Royal Marsden NHS Foundation Trust

\section{Shaman Jhanji}

Royal Marsden Hospital NHS Trust: Royal Marsden NHS Foundation Trust

Joanne Droney

Royal Marsden Hospital NHS Trust: Royal Marsden NHS Foundation Trust

\section{Research Article}

Keywords: Trigger Tools, Palliative Care, ICU, Referral Criteria, End of Life

Posted Date: April 26th, 2021

DOI: https://doi.org/10.21203/rs.3.rs-307793/v1

License: (c) (i) This work is licensed under a Creative Commons Attribution 4.0 International License. Read Full License

Version of Record: A version of this preprint was published at Supportive Care in Cancer on October 26th, 2021. See the published version at https://doi.org/10.1007/s00520-021-06542-w. 


\section{Abstract}

\section{Introduction}

Palliative care within Intensive Care Units (ICU) benefits decision making, symptom control and end-of-life care. It has shown to reduce length of ICU stay and the use of non-beneficial and unwanted lifesustaining therapies. However, it is often initiated late or not at all. There is increasing evidence behind screening ICU patients using certain criteria or "triggers".

The aim of the project was to assess the need for palliative care referral during ICU admission using "Trigger" tools.

\section{Methods}

Electronic patient record review of cancer patients who died in or within 30 days of discharge from oncology ICU 2016-18.

Patients referred to palliative care prior to or during ICU admission were identified. Three sets of palliative care referral "triggers" were applied: one that is being tested locally and two internationally derived tools. The proportion of patients who met any of these triggers during their final ICU admission was calculated.

\section{Results}

Patients included:149. Median age: 65 years (range 20-83).

Unplanned ICU admissions: 89\%.

Most common diagnoses: Haemato-oncology (32\%); gastrointestinal cancer (22\%).

Patients not known to palliative care team before ICU admission: $73 \%$

Patients referred to palliative care from ICU admission to death: $44 \%$

The overall median time (range) between palliative care referral and death: 0 (0-19) days.

$97 \%$ to $99 \%$ patients warranted referral to palliative care on admission to ICU, using the internationally and locally derived trigger tools.

\section{Conclusion}

All "Triggers" tools identified a high proportion of patients who may have benefitted from palliative care referral on admission to ICU.

\section{Background}


In recent years data has shown that there has been an increasing number of cancer patients benefiting from intensive care support (1). Initiation of a 'trial of intensive care unit (ICU) therapy' in patients with advanced cancer is becoming more common (1). It is estimated that $18-30 \%$ of cancer patients use intensive care services $(2,3)$. ICU mortality for cancer patients admitted to ICU are approximately $27-43 \%$ $(3,4,5)$, not dissimilar to general ICU patients however and there are a proportion of cancer patients who survive their ICU stay only die several months later from their underlying cancer (6). Being able to identify those cancer patients who may benefit from palliative care input at an early stage is key (7).

Early involvement of palliative care for patients with cancer has been proven in studies to improve patient experience, reduce symptom burden, support communication, and promote patient choice $(8,9,10,11$, 12). Furthermore, early palliative care has been shown to reduce the use of acute care services including inpatient hospital admissions and emergency department attendances $(13,14,15)$. Within the ICU setting the delivery of palliative care has shown to benefit decision making and symptom control, as well as reducing the length of ICU stay and the use of non-beneficial and unwanted life sustaining therapies (7, $13,16,17)$.

Prominent organisations such as The World Health Organisation, the European Society for Medical Oncology (18) and the American Society of Clinical Oncology (19) recommend that palliative care should be delivered early on, alongside standard oncology care, thereby ensuring patients with or at risk of unmet palliative care needs are identified proactively $(20,21)$.

However, there are several barriers to palliative care referral, and it is often initiated late in the course of a critical illness $(13,14,22)$. Identification of patients who may benefit from palliative care review in the ICU and the best time to refer them to the speciality has been the subject of several studies and reviews. (23, 24). There is increasing evidence behind screening ICU patients using referral criteria or "triggers" $(13,24$, $25,26,27,28)$; as this may help to identify those patients who would benefit from a formal assessment of palliative care needs and offer a pragmatic approach to integrating palliative care.

The aims of this study were to

1. examine how many patients, who died on a cancer-specific ICU or within a month of ICU discharge, were referred to palliative care prior to death

2. Identify the proportion of patients who may have been referred to palliative care if a palliative care referral "Trigger" too had been used, either within 6 months prior to ICU admission or during ICU admission.

The project was split into two parts - in part one the referrals to palliative care in the 6 months prior to ICU admission were examined. Part two focused on the palliative care referrals made in ICU. In both parts of the project a number of trigger tools were retrospectively applied to explore the potential impact of each individual tool on palliative care referrals.

\section{Methods}




\section{Setting and cohort}

This study was approved as a service evaluation by the Royal Marsden Committee for Clinical Research. This study was carried out in a 269-bedded specialist adult cancer hospital located across two sites in London. The hospital is a tertiary referral centre for patients with cancer from across the United Kingdom and abroad. There is a 16-bedded mixed medical and surgical ICU, which admits approximately 1,400 patients per year and has capacity for both level 2 (single organ support, or extensively post-operative care) and 3 (two or more organ support, or advanced respiratory support) care.

The study included all patients who had died either in ICU or within 30 days of an ICU admission during a two-year period, between 01/04/2016 and 31/03/2018. There were no exclusion criteria.

\section{Study design}

This was a two-part retrospective study with the first part relating to palliative care referral prior to ICU admission and the second relating to palliative care referral during ICU admission.

An initial literature review was carried out to identify palliative care referral trigger tools for inclusion in this study. A thorough literature search was conducted to find these tools, using the keywords "trigger tools" and "intensive care". To date there is no evidence as to the most effective trigger tool in this setting. We adopted a pragmatic approach to deciding on the tools for inclusion in this study i.e. those with which we had clinical experience, those which had been devised with international input and those which had been evaluated in this particular clinical setting (Table 1). For the first part of the study, we included a palliative care referral "Trigger" tool that was developed at our centre and against which we have previously tested against acute oncology admissions (29). We also included a set of palliative care referral criteria for outpatient specialty palliative care which was devised through a process of international Delphi consensus (30). For the second part of the study we included two international trigger tools; BMJ Triggers (7) - evaluates a new 7-point screening tool, which screened over 600 patients at 4 different ICUs and found only 5 of the criteria to be relevant. Hua et al Triggers (16) is the other international screening tool, which evaluates the use of a 5-point screening tool for palliative care referral on ICU admissions.

An initial review was carried out to evaluate patients' demographics, cancer type and stage, date and cause of death and the number of days between the last palliative care referral and death. For part one of the study we reviewed the patient records for the six months prior to ICU admission. We identified patients who had been referred to palliative care during this time and recorded the reason for this referral and the number of days between this referral and ICU admission. The two trigger tools, described above, were then applied to the data to assess which patients would have been identified for a palliative care referral, based on whether they were positive for any of the palliative care referral "triggers".

In part two of the study, we investigated: the reason for ICU admission (20); when, if at all, patients had been referred to palliative care during their ICU admission and the reason for this. Three different trigger 
tools, described above, were then used to assess which patients would have been identified for a palliative care referral, and the earliest they would have become positive for them. Throughout the study patients were considered positive for a "trigger" tool if they met one of "triggers".

Patient records were examined using the Electronic Patient Record (EPR), IntelliView Clinical Information Portfolio (ICIP), and written notes. Data were collected by two investigators. All data were entered onto a database. Data were pseudo-anonymised and dealt with Good Clinical Practice guidelines and General.

\section{Data analysis}

Data were described using descriptive methods. Median and range were used to describe continuous nonparametric clinical data, with counts and percentages used for discrete variables. 
Table 1

Trigger Tools used in study

\begin{tabular}{|c|c|c|c|c|}
\hline $\begin{array}{l}\text { Palliative } \\
\text { Care } \\
\text { Referral } \\
\text { "Trigger" } \\
\text { Tool }\end{array}$ & $\begin{array}{l}\text { Hui Trigger } \\
\text { Tool }(30)\end{array}$ & $\begin{array}{l}\text { Royal Marsden Trigger } \\
\text { (locally derived tool) (29) }\end{array}$ & $\begin{array}{l}\text { Zalenski Trigger } \\
\text { tool (7) }\end{array}$ & $\begin{array}{l}\text { Hua et al } \\
\text { Triggers (16) }\end{array}$ \\
\hline Description & $\begin{array}{l}\text { 12-point tool } \\
\text { used for } \\
\text { outpatient } \\
\text { speciality } \\
\text { palliative care }\end{array}$ & $\begin{array}{l}\text { Developed from expert } \\
\text { consensus at Royal Marsden } \\
\text { Hospital, 7-point palliative } \\
\text { care referral trigger tool used } \\
\text { in the oncology outpatients }\end{array}$ & $\begin{array}{l}\text { 5-point trigger tool } \\
\text { used to determine } \\
\text { which ICU } \\
\text { patients require a } \\
\text { palliative care } \\
\text { referral }\end{array}$ & $\begin{array}{l}\text { 5-point } \\
\text { trigger tool } \\
\text { used to } \\
\text { screen } \\
\text { patients } \\
\text { admitted to } \\
\text { ICU }\end{array}$ \\
\hline \multirow{10}{*}{$\begin{array}{l}\text { Palliative } \\
\text { Care } \\
\text { referral } \\
\text { criteria } \\
\text { within } \\
\text { each } \\
\text { "Trigger" } \\
\text { Tool }\end{array}$} & $\begin{array}{l}\text { Severe } \\
\text { physical } \\
\text { symptom }\end{array}$ & $\begin{array}{l}\text { Metastatic cancer } \\
\text { progressing after first line of } \\
\text { treatment }\end{array}$ & Advanced Cancer & $\begin{array}{l}\text { ICU } \\
\text { admission } \\
\text { after hospital } \\
\text { stay of } \\
\text { 10days or } \\
\text { more }\end{array}$ \\
\hline & & & & $\begin{array}{l}\text { Multisystem } \\
\text { organ failure } \\
\text { of } 3 \text { or more } \\
\text { systems }\end{array}$ \\
\hline & $\begin{array}{l}\text { Severe } \\
\text { emotional } \\
\text { symptom }\end{array}$ & $\begin{array}{l}\text { Performance status ECOG } 2 \\
\text { and deteriorating }\end{array}$ & $\begin{array}{l}\text { ICU stay }>5 \text { days } \\
\text { or readmission } \\
\text { within 30days }\end{array}$ & $\begin{array}{l}\text { Diagnosis of } \\
\text { stage IV } \\
\text { malignancy }\end{array}$ \\
\hline & $\begin{array}{l}\text { Hastened } \\
\text { Death }\end{array}$ & $\begin{array}{l}\text { Acute oncology or unplanned } \\
\text { admission }\end{array}$ & $\begin{array}{l}\text { Admission post } \\
\text { arrest }\end{array}$ & $\begin{array}{l}\text { Post cardiac } \\
\text { arrest }\end{array}$ \\
\hline & $\begin{array}{l}\text { Spirtual and } \\
\text { existential } \\
\text { crisis }\end{array}$ & $\begin{array}{l}\text { Severe or overwhelming } \\
\text { symptoms }\end{array}$ & $\begin{array}{l}\text { Team perceived } \\
\text { need for palliative } \\
\text { care }\end{array}$ & $\begin{array}{l}\text { Intracerebral } \\
\text { haemorrhage } \\
\text { requiring } \\
\text { ventilation }\end{array}$ \\
\hline & $\begin{array}{l}\text { Assistance } \\
\text { with decision } \\
\text { making }\end{array}$ & $\begin{array}{l}\text { Anorexia, hypercalcaemia or } \\
\text { any effusion }\end{array}$ & $\begin{array}{l}\text { Admitted from } \\
\text { nursing facility }\end{array}$ & \\
\hline & Patient request & $\begin{array}{l}\text { Moderate or severe } \\
\text { psychological or existential } \\
\text { distress }\end{array}$ & & \\
\hline & Delirium & Complex social issues & & \\
\hline & $\begin{array}{l}\text { Brain } \\
\text { metastases }\end{array}$ & & & \\
\hline & $\begin{array}{l}\text { Spinal cord } \\
\text { compression }\end{array}$ & & & \\
\hline
\end{tabular}




\begin{tabular}{|c|c|c|c|c|}
\hline $\begin{array}{l}\text { Palliative } \\
\text { Care } \\
\text { Referral } \\
\text { "Trigger" } \\
\text { Tool }\end{array}$ & $\begin{array}{l}\text { Hui Trigger } \\
\text { Tool (30) }\end{array}$ & $\begin{array}{l}\text { Royal Marsden Trigger } \\
\text { (locally derived tool) (29) }\end{array}$ & $\begin{array}{l}\text { Zalenski Trigger } \\
\text { tool (7) }\end{array}$ & $\begin{array}{l}\text { Hua et al } \\
\text { Triggers (16) }\end{array}$ \\
\hline & $\begin{array}{l}\text { Within } 3 \\
\text { months of } \\
\text { diagnosis of } \\
\text { advanced with } \\
\text { median } \\
\text { survival of } 1 \\
\text { year }\end{array}$ & & & \\
\hline & $\begin{array}{l}\text { Progression on } \\
\text { second line } \\
\text { systemic } \\
\text { therapy }\end{array}$ & & & \\
\hline
\end{tabular}

\section{Results}

149 patients were included in this analysis. The median age of patients was 65 years (range 20-83 years). The most common diagnoses were haematological malignancies $(31 \%, n=46)$, followed by gastrointestinal malignancies $(16 \%, n=24)$. Evaluation of the data revealed that $89 \%(n=134)$ of the ICU admissions, were unplanned. The most common reasons for ICU admission were other, which was mostly post-operative complications, respiratory failure and sepsis. The median length of ICU admission before death was 5 days, with a range of 0 to 70 days.

Sixty two percent of patients $(n=92)$ were referred to palliative care prior to death, 37 of these patients were referred to palliative care prior to ICU admission. That is only $25 \%$ of patients were referred to palliative care prior to ICU admission. The median time between the first palliative care referral and death was 11 days, with the range being between 0 and 1145 days.

During ICU admission only $56 \%$ of patients $(n=84)$ were referred to palliative care. Out of these 84 patients $35 \%(n=29)$, were already known to palliative care prior to admission to ICU. There were 8 patients who had previously been referred to and were known to palliative care but were not referred during their ICU admission.

Of the patients who were referred to palliative care, the referrals were not only done quite late into their ICU admission but also close to death. The median number of days between ICU admission and referral was 7, with the range being between 2 and 24 . The median number of days between palliative care referral in ICU and death was 0 with a range of 0 to 19; showing that the majority of patients who did get a palliative care referral, were only referred to palliative care on the day of their death.

It was found that $38 \%$ of patients $(n=57)$ were not referred to palliative care at all before death. 
After applying the locally derived "Royal Marsden Trigger tool" to the data set from part 1, results showed that $71 \%(n=106)$ of the patients met the criteria that suggested a palliative care referral would have been appropriate, prior to ICU admission. Application of the internationally derived "Delphi" trigger tool suggested that $59 \%(n=88)$ of the patients would have warranted a palliative care referral in the 6 months prior to their admission to ICU.

Analysis of the data from part 2 of the study showed that a high percentage of patients would have met the criteria for a palliative care referral on admission to ICU. The locally derived "Royal Marsden Trigger tool", recommended that $97 \%$ of the patients $(n=146)$ met the criteria for a palliative care referral on admission to ICU. The ICU specific international trigger tools, BMJ Triggers and Hua et al Triggers recommended that $99 \%(n=149)$ and $97 \%(n=146)$ of patients would have warranted a palliative care referral on admission to ICU, respectively.

Further evaluation of the data revealed that the use of the international ICU specific tools would have also resulted in a palliative care referral being made much earlier before death, allowing the patients and their families to have the full support of palliative care for longer. All patients who were positive for BMJ Trigger tools and Hua et al Triggers, met any one of the criteria for the tool on the day of their ICU admission. The median number of days between becoming positive for the trigger tool and death was 8 (range 0 to 70 days).

Table 2

Retrospective application of Trigger tools to the data

\section{Part 1 prior to ICU admission}

RM Triggers Delphi

Number (\%) of patients meeting any one of the Trigger criteria during the $106(71)$ six months prior to ICU admission

Part 2 during ICU admission

RM BMJ HUA
Triggers

Number (\%) of patients meeting any one of the Trigger criteria during ICU admission

143

(96)
146

(98)
$88(59)$

\section{Discussion}

In this retrospective study we found that most patients were not referred to palliative care both in the months leading up to their final ICU admission or even during it. In the small proportion of patients who were referred to palliative care, the referral was done very late when patients were days away from death. The study showed that the use of a palliative care referral "trigger" tools would have identified a high proportion of patients who may have benefitted from palliative care referral, consistent with findings from other studies. $(7,25,26,27,28,29)$ 
Our results indicate that $75 \%$ of patients were unknown to palliative care in the lead up to their ICU admission. $(13,17)$

Furthermore, results showed that only $56 \%(n=84)$ patients were referred to palliative care during their ICU admission and out of these 29 patients were previously known to palliative care. This means that whilst in ICU 55 patients were referred to palliative care for the first time. We can also see that all the referrals done in ICU were made quite late into the admission. Out of the 84 patients that were referred 52 , $62 \%$ were referred to palliative care on the day of their death.

The results from the retrospective application of trigger tools to the data suggests that there is a large proportion of patients who could have been identified for a palliative care referral and all the benefits that come with it, both before ICU admission and during it. The use of trigger tools in an outpatient setting suggests that between $59-71 \%$ of patients should have been seen by palliative care prior to their ICU admission. These patients may have benefitted from advance care planning and shared decision making which may have impacted on the decision for ICU. $(13,17)$ Additionally this data shows us that the vast proportion of cancer patients warrant palliative care reviews many months before becoming acutely unwell and requiring admission to ICU. This is also reflected in a trigger tools study conducted by Gemmell et al, which found a high percentage of cancer patients warranted a palliative care assessment earlier on in their disease trajectory (29). Looking at the use of trigger tools during ICU admission, we can see that 140 to 148 patients met the criteria for a palliative care referral whilst in ICU, which is more than double the number of patients that were referred in this cohort.

Whilst all the trigger tools picked up higher numbers of patients to refer to palliative care, they also identified patients for referral at an earlier stage. All the patients that were identified by the three trigger tools during ICU admission, were positive from the day of ICU admission. This meant that the median number of days between becoming positive for BMJ and Hua et al trigger tools and death was 8 , compared to actual practice where most patients were referred to palliative care on the day of death. This would have allowed more time for patients and their families to benefit from a palliative care review and could have had a positive effect on patient care. $(13,14,17)$

The selected trigger tools for this study were found through extensive literature searches, as described above. The tools were selected as they not only appeared to be most relevant to our cohort but were also backed by the most robust evidence $(7,16,28,29,30)$. The Hua et al and BMJ trigger tools, were used on more general ICU populations and hence have an evidence base in the group. However, as this study has investigated ICU patients who have cancer, there are a few triggers that are less relevant and others which are more likely to be positive due to the patient demographic. For example, we found that no patients were positive for "Admitted from a nursing facility", whilst triggers relating to advanced or metastatic cancer were positive in $93-94 \%$ of the patients. Future research is needed to refine palliative care referral criteria which are specific for a cancer population. The ICU specific tools (Hua Tool and Zalenski Tool) identified a similar proportion of patients for referral as the non-ICU specific Royal Marsden Tool which has been previously tested in the outpatient setting. This may suggest that it is the use of a targeted 
approach to the identification of patients for referral that matters most, rather than differences between the actual items included in the tools.

One of the main limitations of this study was that the data were collected retrospectively therefore is very reliant on the accuracy, completeness and quality of documentation. Also, regarding the trigger tools themselves, although most of the "triggers" were objective, there were also some subjective "triggers". Therefore, the results may include some bias on part of the data collector and may have varied if purely objective "triggers" had been used, such as "Team perceived need for palliative care". For example, one of the triggers included in both the Hua and Zolenski Tools used in part 2 was around having advanced/metastatic cancer. Although this is quite clear cut in solid organ tumours, it is more difficult to define in haematological malignancies so was down to the authors' discretion on a case by case basis. It could be also argued that the findings are limited to the results of a single, tertiary centre. However, the authors believe that the findings have wider applicability and add to the growing evidence which supports the use of palliative care referral trigger tools.

\section{Conclusion}

This study has demonstrated that the use of specific sets of "trigger" tools may help to highlight the patients in need of a referral to palliative care. The findings demonstrate that use of a trigger tool would identify most patients during their ICU admission, and many patients in the preceding six months prior. This supports the shift in the perception of palliative care; so that it is not only considered at the end of life but is being thought of much earlier in patients' disease course. The use of these trigger tools and early palliative care referral we hope will streamline referral pathways and help with decision making about appropriate treatment and patient centred care.

Our findings lend support to the plausibility of using trigger tools to deliver palliative care to critically ill cancer patients in clinical practice. Although the results are from a small sample size in a single tertiary centre, we believe they have wide applicability, and demonstrate that there is a clear need for the validation of such trigger tools in general and cancer specific populations.

\section{Declarations}

\section{Funding}

The authors did not receive support from any organization for the submitted work.

\section{Conflicts of interest/Competing interests}

The authors have no conflicts of interest to declare that are relevant to the content of this article.

Availability of data and material 
The data came from a private repository, only accessible by members of Royal Marsden NHS Foundation Trust. The data can be made available upon reasonable request from the corresponding author.

\section{Ethics approval}

Ethical approval was granted by the Royal Marsden NHS Foundation Trust Service Evaluation Department.

\section{Consent to participate}

Not applicable

\section{Consent for publication}

Not applicable

\section{Authors' contributions}

Joanne Droney, Pascale Gruber and Shaman Jhanji conceived the idea and planned the study.

Yashna Nadkarni and Ivana Kukec collected the data, with supervision from Joanne Droney, Pascale Gruber and Shaman Jhanji.

Joanne Droney, Ivana Kukec and Yashna Nadkarni analysed the data.

All authors reviewed, discussed and contributed to the interpretation of the results and writing of the manuscript.

All authors agree on the final version of the manuscript.

\section{Funding}

The authors did not receive support from any organization for the submitted work.

\section{Conflicts of interest/Competing interests}

The authors have no conflicts of interest to declare that are relevant to the content of this article.

Availability of data and material

The data came from a private repository, only accessible by members of Royal Marsden NHS Foundation Trust. The data can be made available upon reasonable request from the corresponding author.

\section{Ethics approval}

Ethical approval was granted by the Royal Marsden NHS Foundation Trust Service Evaluation Department. 
$\underline{\text { Consent to participate }}$

Not applicable

$\underline{\text { Consent for publication }}$

Not applicable

\section{References}

1. Azoulay E, Soares M, Darmon M, Benoit D, Pastores S, Afessa B (2011) Intensive care of the cancer patient: recent achievements and remaining challenges. Ann Intensive Care [Internet]. [cited 2020 Nov 8];1(1). Available from: 10.1186/2110-5820-1-5

2. Soares M, Caruso P, Silva E, Teles JMM, Lobo SMA, Friedman G et al (2010) Characteristics and outcomes of patients with cancer requiring admission to intensive care units: A prospective multicenter study*. Critical Care Medicine [Internet]. [cited 2020 Nov 8];38(1):9-15. Available from: 10.1097/CCM.0b013e3181c0349e

3. de Jonge E, Bos MM (2009) Patients with cancer on the ICU: the times they are changing. Critical Care [Internet]. [cited 2020 Nov 8];13(2):122. Available from: 10.1186/cc7721

4. Lecuyer L, Chevret S, Thiery G, Darmon M, Schlemmer B, Azoulay É (2007) The ICU Trial: A new admission policy for cancer patients requiring mechanical ventilation*. Critical Care Medicine [Internet]. [cited 2020 Nov 8];35(3):808-14. Available from: 10.1097/01.ccm.0000256846.27192.7a

5. McGrath S, Chatterjee F, Whiteley C, Ostermann M (2010) ICU and 6-month outcome of oncology patients in the intensive care unit. QJM [Internet]. [cited 2020 Nov 8];103(6):397-403. Available from: 10.1093/qjmed/hcq032

6. Gay EB, Weiss SP, Nelson JE (2012) Integrating palliative care with intensive care for critically ill patients with lung cancer. Ann Intensive Care [Internet]. [cited 2020 Nov 8];2(1):3. Available from: $10.1186 / 2110-5820-2-3$

7. Zalenski R, Courage C, Edelen A, Waselewsky D, Krayem H, Latozas J et al (2014) Evaluation of screening criteria for palliative care consultation in the MICU: a multihospital analysis. BMJ Support Palliat Care [Internet]. [cited 2020 Nov 8];4(3):254-62. Available from: 10.1136/bmjspcare-2013000570

8. Bakitas M, Lyons KD, Hegel MT, Balan S, Brokaw FC, Seville J et al (2009) Effects of a palliative care intervention on clinical outcomes in patients with advanced cancer: the Project ENABLE II randomized controlled trial. JAMA 302(7):741-749

9. Temel JS, Greer JA, El-Jawahri A, Pirl WF, Park ER, Jackson VA et al (2017) Effects of Early Integrated Palliative Care in Patients With Lung and GI Cancer: A Randomized Clinical Trial. J Clin Oncol 35(8):834-841

10. Zimmermann C, Swami N, Krzyzanowska M, Hannon B, Leighl N, Oza A et al (2014) Early palliative care for patients with advanced cancer: a cluster-randomised controlled trial. Lancet 
383(9930):1721-1730

11. Temel JS, Greer JA, Muzikansky A, Gallagher ER, Admane S, Jackson VA et al (2010) Early palliative care for patients with metastatic non-small-cell lung cancer. N Engl J Med 363(8):733-742

12. Vanbutsele G, Van Belle S, De Laat M, Surmont V, Geboes K, Eecloo K et al (2015) The systematic early integration of palliative care into multidisciplinary oncology care in the hospital setting (IPAC), a randomized controlled trial: the study protocol. BMC Health Serv Res [Internet] 15:554

13. O'Mahony S, McHenry J, Blank AE, Snow D, Eti Karakas S, Santoro G, Selwyn P, Kvetan V (2010) Preliminary report of the integration of a palliative care team into an intensive care unit. Palliat Med 24:154-165

14. Norton SA, Hogan LA, Holloway RG, Temkin-Greener H, Buckley MJ, Quill TE (2007) Proactive palliative care in the medical intensive care unit: effects on length of stay for selected high-risk patients. Crit Care Med 35:1530-1535

15. Kistler E, Stevens E, Scott E, Philpotts L, Greer J, Greenwald J (2020) Triggered Palliative Care Consults: A Systematic Review of Interventions for Hospitalized and Emergency Department Patients. J Pain Symptom Manage 60(2):460-475

16. Hua M, Li G, Blinderman C, Wunsch H (2014) Estimates of the Need for Palliative Care Consultation across United States Intensive Care Units Using a Trigger-based Model. Am J Respir Crit Care Med 189(4):428-436

17. Campbell ML, Guzman JA (2003) Impact of a proactive approach to improve end-of-life care in a medical ICU. Chest 123:266-271

18. Metastatic non-small-cell (2016 Sep) lung cancer: ESMO Clinical Practice Guidelines for diagnosis, treatment and follow-up. Ann Oncol 27(suppl 5):v1-v27 et al

19. Ferrell BR, Temel JS, Temin S, Alesi ER, Balboni TA, Basch EM et al (2017) Integration of Palliative Care Into Standard Oncology Care: American Society of Clinical Oncology Clinical Practice Guideline Update. J Clin Oncol [Internet] 35(1):96-112

20. Miller SJ, Desai N, Pattison N, Droney JM, King A, Farquhar-Smith P et al (2015) Quality of transition to end-of-life care for cancer patients in the intensive care unit. Ann Intensive Care [Internet]. [cited 2020 Nov 8];5(1). Available from: 10.1186/s13613-015-0059-7

21. Thomas K et al, Prognostic Indicator Guidance 4th Edition Oct 2011, Gold Standards Framework centre in end of life care. SPICT- Supportive and Palliative Care Indicators Tool- the University of Edinburgh

22. Le BH, Watt JN (2010) Care of the dying in Australia's busiest hospital: benefits of palliative care consultation and methods to enhance access. J Palliat Med 13:855-860

23. Nelson JE, Bassett R, Boss RD et al (2010) Models for structuring a clinical initiative to enhance palliative care in the intensive care unit: A report from the IPAL-ICU Project. Crit Care Med 38:17651772

24. Nelson JE, Curtis JR, Mulkerin C et al (2013) Choosing and using screening criteria for palliative care consultation in the ICU: A report from the improving palliative care in the ICU (IPAL-ICU) Advisory 
Board. Crit Care Med 41:2318-2327

25. Nelson JE, Campbell ML, Cortez TB et al (2010) Organizing an ICU Palliative Care Imitative: a technical assistance monograph from The IPAL-ICU Project. http://ipal.capc.org/downloads/ ipal-icuorganizing-an-icu-palliative-care-initiative.pdf (accessed November, 2013)

26. Nelson JE, Curtis JR, Mulkerin C, Campbell M, Lustbader DR, Mosenthal AC, Puntillo K, Ray DE, Bassett R, Boss RD et al (2013) Improving Palliative Care in the ICU (IPAL-ICU) Project Advisory Board. Choosing and using screening criteria for palliative care consultation in the ICU: a report from the Improving Palliative Care in the ICU (IPAL-ICU) Advisory Board. Crit Care Med 41:2318-2327

27. Lupu D, American Academy of Hospice and Palliative Medicine Workforce Task Force (2010) Estimate of current hospice and palliative medicine physician workforce shortage. J Pain Symptom Manage 40:899-911

28. Hill A, Dawood S, Boland A, Leahy E, EM Murtagh H F. Palliative medicine in the intensive care unit: needs, delivery, quality. BMJ Supportive \& Palliative Care. 2021;:bmjspcare-2020-002795

29. Gemmell R, Yousaf N, Droney J. "Triggers" for early palliative care referral in patients with cancer: a review of urgent unplanned admissions and outcomes. Support Care Cancer [Internet] (2020) [cited 2020 Nov 8];28(7):3441-9. Available from: 10.1007/s00520-019-05179-0

30. Hui D, Mori M, Watanabe SM, Caraceni A, Strasser F, Saarto T et al (2016) Referral criteria for outpatient specialty palliative cancer care: an international consensus. The Lancet Oncology [Internet]. [cited 2020 Nov 8];17(12):e552-9. Available from: 10.1016/s1470-2045(16)30577-0

\section{Supplementary Files}

This is a list of supplementary files associated with this preprint. Click to download.

- Appendix.docx 